\title{
MOBILIDADE PENDULAR E CENTRALIDADE ESPACIAL DA REGIÃO METROPOLITANA DE BELO HORIZONTE
}

\author{
Carlos Lobo \\ Leandro Cardoso ${ }^{\mathbf{\beta}}$ \\ Ralfo Matos
}

\section{Resumo}

As grandes cidades brasileiras, sobretudo aquelas com rápido crescimento a partir de meados do século passado, vêm apresentando, notadamente nas últimas três décadas, sinais de desconcentração espacial, descentralização econômica e redistribuição da população. Diversos fatores têm favorecido essa tendência, tais como os relacionados aos custos sociais resultantes de processos como deseconomias de aglomeração, além das políticas públicas destinadas a melhorar a distribuição de atividades e oportunidades. A atual organização espacial da Região Metropolitana de Belo Horizonte parece confirmar essas hipóteses. Desde a década de 1970, muitos municípios da periferia, vêm apresentando incrementos populacionais mais expressivos, resultado, em boa medida, do grande volume de emigrantes procedentes do núcleo metropolitano. Essa dispersão espacial da população também teve seus reflexos na distribuição da produção de riquezas na região, o que pode ser demonstrado pela perda de participação relativa do PIB de Belo Horizonte nas últimas décadas. O propósito desse estudo é avaliar o nível de dependência econômica dos municípios periféricos da RMBH em relação ao núcleo metropolitano com base nos deslocamentos espaciais diários da população. Os Censos Demográficos de 1980 e 2000 e as Pesquisas Domiciliares de Origem e Destino (OD’s) de 1992 e 2001 foram as principais fontes de dados dessa pesquisa, a partir das quais foi possível identificar, na maior parte dos municípios periféricos, a redução no volume dos deslocamentos com destino ao núcleo metropolitano. Quando os movimentos têm como motivo o trabalho, conforme informações obtidas a partir dos deslocamentos identificados nas pesquisas OD, essa redução na centralidade metropolitana torna-se ainda mais relevante. Mesmo que Belo Horizonte tenha mantido sua notória centralidade e continue atraindo um expressivo volume dos movimentos de população na região, há um sensível redirecionamento nos movimentos pendulares. Favorecendo o crescimento da população que trabalha no próprio município de residência.

Palavras-chave: Mobilidade pendular; desconcentração espacial; autonomia municipal.

\footnotetext{
- Geógrafo. Doutorando em Geografia pelo IGC/UFMG. Professor/Pesquisador do curso de Geografia e Análise Ambiental do Uni-BH.

* Doutor em Geografia pelo IGC/UFMG. Professor do curso de Geografia e Análise Ambiental do Uni-BH.

- Doutor em Demografia. Professor Adjunto do Departamento de Geografia, IGC/UFMG.
} 


\section{1- INTRODUÇÃO}

Uma das questões que atualmente tem atraído grande atenção no âmbito dos estudos populacionais refere-se ao processo de desconcentração espacial da população e das atividades econômicas. Além das recorrentes controvérsias sobre esses processos, que resultaram na difusão de expressões como "desmetropolização", "reversão da polarização", "desconcentração concentrada", "dispersão espacial”, dentre outras, há pelo menos um relativo consenso acerca das evidências empíricas de queda no ímpeto de crescimento populacional dos grandes centros metropolitanos brasileiros nas últimas décadas do século passado. Embora o processo de urbanização no Brasil seja bastante recente, os dados referentes aos dois últimos Censos Demográficos parecem confirmar a tendência à dispersão espacial da população, mesmo que os principais centros metropolitanos tenham mantido sua expressão demográfica regional e continuado a atrair expressivos contingentes populacionais (Martine, 1994; Diniz, 1993; Matos, 1995a; Brito, 1992).

A atual distribuição espacial da população na Região Metropolitana de Belo Horizonte parece confirmar essa tendência. Desde a década de 1970, muitos municípios da periferia, vêm apresentando incrementos populacionais mais expressivos, resultado, em boa medida, do grande volume de emigrantes procedentes do núcleo metropolitano. Essa dispersão espacial da população também teve seus reflexos na distribuição da produção de riquezas na região, o que pode ser demonstrado pela perda de participação relativa do PIB de Belo Horizonte nas últimas décadas. Cabe destacar que, afora as contribuições da economia regional, esse debate ainda requer aprofundamento quanto aos efeitos da distribuição espacial da população e dos movimentos espaciais da população. No âmbito da Geografia, são raros os trabalhos sobre esses movimentos e mais incomuns ainda aqueles que se utilizam outras informações além das bases censitárias.

Nesse aspecto, o propósito desse paper é avaliar o nível de centralidade do núcleo metropolitano com base nos deslocamentos espaciais diários da população. Para tanto, utilizouse além dos microdados da amostra dos Censos Demográficos de 1980 e 2000, as bases das Pesquisas Domiciliares de Origem e Destino (ODs) de 1992 e 2001. A partir dessas bases foi possível identificar os movimentos específicos de residência para o local de trabalho. A análise do volume e das principais características dos indivíduos protagonistas desses fluxos permitiu a inclusão de dimensões pouco exploradas na abordagem nos estudos sobre o processo de desconcentração e dispersão espacial da população. 


\section{2- REVERSÃO DA POLARIZAÇÃO, DESCONCENTRAÇÃO CONCENTRADA OU DESENVOLVIMENTO POLIGONAL?}

Uma obra de referência na discussão sobre o processo de reversão da polarização foi elaborada por Richardson (1980). O crescimento continuado da concentração não leva a um perpétuo aumento da eficiência econômica. Os benefícios marginais derivados da escala urbana e da concentração tendem a diminuir a partir de certo tamanho de população. Os custos médios de prover infraestrutura física, serviços públicos e administração governamental local aumentam em termos per capita com o crescimento da cidade. A relação custo-benefício altera-se a favor de custos crescentes. Richardson acredita que o ponto de inflexão médio e os custos sociais marginais refletem o começo de crescentes deseconomias de aglomeração, que ocorrem em função do incremento da congestão e contaminação (em conjunto com os fatores sociais tais como aumento da criminalidade e da marginalidade); da elevação no preço médio da terra (que passa a sofrer concorrência entre usos alternativos de solo) e do trabalho (aumento do custo de vida devido aos custos crescentes de transporte e habitação, explicados em parte pelas altas do preço da terra).

Para esse autor, esse processo caracteriza-se pela mudança de tendência de polarização espacial na economia nacional, a partir do qual ocorreria a dispersão espacial para fora da região central. Richardson acredita que a reversão da polarização se dá a partir de em uma sequência de fases: no início haveria um processo bem definido de concentração econômica, quando era estabelecido um centro e uma periferia; em sequência ocorreriam transformações estruturais na área central, em que os núcleos adjacentes passariam a apresentar crescimento mais acelerado que o centro; o terceiro estágio marcaria o início do processo de reversão da polarização, quando haveria uma dispersão ampliada; na sequência a dispersão também atingiria os centros secundários; e finalmente a área central começaria a perder população ${ }^{1}$. Dessa forma, a medida que as oportunidades de emprego começam a expandir-se mais rapidamente fora da principal área metropolitana, a população residencial tenderá a redistribuirse ao longo de todo o sistema urbano, refletindo as crescentes vantagens comparativas das cidades secundárias. Os fluxos de capital e de trabalho começam a convergir para fora da metrópole central até cidades secundárias, induzindo taxas relativamente mais rápidas de crescimento econômico e demográfico.

\footnotetext{
${ }^{1}$ Richardson analisou os casos do Japão e Coréia, onde supostamente teria ocorrido o processo de reversão da polarização. Contudo, a experiência americana, com a perda expressiva de população das grandes cidades do nordeste e o grande crescimento dos centros do Sul do país, é aquela que mais se aproxima do modelo proposto.
} 
$\mathrm{Na}$ literatura econômica são indicadas as seguintes condições para a existência do processo de reversão da polarização: a) existência de pleno emprego; b) aparecimento de deseconomias de aglomeração; c) ocorrência de efeitos de espraiamento em larga escala; d) aumento da complexidade organizacional nas atividades empresariais. Contudo, estas são condições difíceis de encontrar em países não desenvolvidos. Em alguns casos, todavia, é exatamente o aparecimento de oportunidades econômicas e o crescimento na oferta de empregos que tem levado pessoas e empresas para fora das áreas metropolitanas. Um ponto de inflexão decisivo, como apontado por Redwood (1984), refere-se ao crescimento das chamadas deseconomias de aglomeração, que incluem fatores sociais, como o aumento da criminalidade urbana, e refletem incrementos pela elevação dos custos de moradia e trabalho. Como bem esclarece Negri (1996), as deseconomias de aglomeração envolvem:

“(...) um conjunto de variáveis, entre as quais se destacam os maiores custos de transportes, de terreno, de serviços e de infra-estrutura urbana, incluindo-se outras que provocam alteração na organização da produção e na sua produtividade, com maiores dispêndios de tempo com transporte, ampliação do poder sindical de classe trabalhadora, questões ambientais, com deteriorização das condições de vida nos grandes centros urbanos, queda na produtividade do trabalho, etc." (NEGRI, 1996, p.15)

No âmbito dos estudos regionais, várias tentativas de aplicação desses modelos e de reconstrução teórica foram utilizadas no caso brasileiro, cujas particularidades estruturais e setoriais vão oferecer dificuldades adicionais a interpretação desse fenômeno. Um dos primeiros trabalhos sobre o possível processo de reversão da polarização no Brasil foi proposto por Townroe e Keen (1984). Ao considerar esse processo a partir do ponto em que a concentração da população urbana na região central começa a decrescer, esses autores acreditavam que havia sinais concretos de reversão da polarização no Estado de São Paulo entre 1970 e 1980. Eles sugerem a dualidade dos fatores que levam à concentração das atividades econômicas, destacando o papel concentrador representado por determinadas forças sociais e econômicas, que a partir de um ponto passariam a atuar na direção oposta: da desconcentração. A transição demográfica, os graus de desigualdade social e econômica, e os padrões de desenvolvimento rural e as formas institucionais e sociais de difusão de informações e inovações podem incrementar ou não a concentração na distribuição da população urbana².

\footnotetext{
2 Em relação ao setor industrial, Redwood (1985) também oferecia evidências sobre o caso brasileiro. Com a constatação da perda da participação do estado de São Paulo a partir de finais da década de 1950, Redwood acreditava que estaria em curso um processo de desconcentração das principais áreas metropolitanas, que favorecia os centros secundários mais próximos. Havia fortes evidências de que os processos de suburbanização, de descentralização urbana e de reversão da polarização se difundiam em todo o sistema urbano.
}

Cadernos do Leste 
É essencial, na interpretação desse mesmo autor, a atenção dirigida às necessidades das cidades secundárias, que cumprem papel fundamental na eficiência econômica e no desenvolvimento regional. No exame do desenvolvimento das cidades secundárias, o autor sugere que certos tipos de atividade industrial tendentes a naturalmente se localizar nestas cidades. As indústrias de bens intermediários baseadas em recursos naturais (química, plásticos, madeira, papel e metalurgia incluindo aço), podem estar localizados próximos de grandes cidades de modo a reduzir custos de transportes valendo-se da proximidade dos mercados. Outro grupo de indústrias se dirige as cidades secundárias por se servirem aos mercados locais protegidos da concorrência externa por custos de transportes relativamente altos. Alguns serviços de maior magnitude e mais especializados, tais como universidades, hospitais, algumas atividades comerciais procuram se instalar em centros médios.

Ainda que possa parecer consensual e bastante atraente, as proposições sobre o possível processo de reversão da polarização no Brasil sofreram inúmeras críticas. As controvérsias vão desde algumas evidências empíricas, até o tipo de variáveis e a metodologia utilizada. Azzoni (1986), por exemplo, critica o fato de o tamanho da cidade ser considerado com indicador de economias aglomerativas. Ao admitir que as vantagens aglomerativas estão presentes no ambiente urbano, a exemplo da linha de polarização psicológica e do transporte de idéias, é imprescindível considerar a região como capaz de gerar um campo de atração sobre novos investimentos. A ideia essencial e que a atração regional transcende o ambiente urbano, enquanto os custos locacionais são essencialmente urbanos. Para Azzoni, é no mínimo apressada a suposição de que haveria um processo de reversão da polarização no Brasil. Pelo contrário,

“(...) as evidências indicam que, longe de constituir-se um sinal de reversão da polarização, o fenômeno observado em São Paulo estaria mais próximo de um espraiamento da indústria dentro da área mais industrializado do país, em um processo do tipo "desconcentração concentrada". Seria aproximadamente um tipo de suburbanização das atividades industriais em âmbito mais abrangente, o que é possível pelas oportunidades abertas pelo desenvolvimento tecnológico, em um sentido amplo, para separação das atividades produtivas das atividades de comando empresarial." (AZZONI, 1986, p.126)

Diniz (1993), ao contestar alguns dos pressupostos e os resultados apresentados por Azzoni, oferece um novo modelo de interpretação. De acordo com esse autor, após a incontestável concentração econômica e demográfica verificada até finais da década de 1960, iniciou-se em um primeiro momento o processo de reversão desta polarização. Entretanto, o processo de desconcentração não teria ocorrido de modo ampliado, e sim, em espaços seletivos bem equipados e ricos em externalidades no país, refletindo-se sobretudo pelo espraiamento para o interior de determinados estados brasileiros. Em uma segunda fase, ocorreria a relativa reconcentração no polígono definido por Belo Horizonte-UberlândiaLondrina/Maringá-Porto Alegre-Florianóplis-São José dos Campos-Belo Horizonte. Diniz Cadernos do Leste 
reforça a abrangência espacial restrita da suposta reversão da polarização para o caso brasileiro.

De acordo com esse autor,

“(...), não parece que esta tendência de reversão em sentido amplo continuará até o final do século. Ao contrário, a grande ênfase em indústrias de alta tecnologia e o relativo declínio e fracasso das políticas regionais e do investimento estatal, abrem uma terceira possibilidade. Nesta o processo de desconcentração será enfraquecido e o crescimento tenderá a se circunscrever ao estado de São Paulo e ao grande polígono em trono dele. Estamos chamando este processo de aglomeração poligonal.” (DINIZ, 1993, p. 54)

Haddad (1980), ao discutir a mesma questão, chegou a assinalar alguns pontos que permitem contestar a tese da desconcentração. Dentre seus argumentos, vale destacar os relativos: às resistências inerciais que se oporiam às alterações do padrão locacional concentrador; às incertezas sobre a existência de condições suficientes para a sustentação de um crescimento acelerado nas periferias; às externalidades ainda atraentes nas áreas sob a influência da grande metrópole, especialmente se retomada a expansão econômica, quando então novos ciclos tecnológicos não poderiam dispensar o ambiente central.

Negri (1996) além de considerar indevida a analogia de Azzoni, acredita ser inapropriado o polígono estabelecido por Diniz. De acordo com Negri, ainda que essa região tenha se beneficiado da desconcentração dos últimos 20 anos, quando ampliou sua participação na indústria nacional de 33,1\% para 49,2\%, isto não foi incompatível com o crescimento fora do polígono. Ao contrário, entre 1970 e 1990, as únicas quedas relativas devem-se à Grande São Paulo (de 34,4\% para 26,4\%) e ao Rio de Janeiro (de 15,7\% para 9,8\%). Enquanto o Nordeste (excluído o estado da Bahia) praticamente manteve o mesmo percentual (de 4,2\% para 4,5\%), Espírito Santo, Bahia e os estados do Norte e Centro-Oeste ampliaram seu peso no total nacional (de 3,6\% em 1970 para 10,2\% em 1990). Esse autor enfatiza a explicação dos determinantes da desconcentração industrial dos anos 70 e 80, associando-aàs diversas obras, programas e políticas deflagradas pelos Governos Federal e Estadual a partir dos anos 70. As políticas de indução da desconcentração na órbita federal (notadamente as contidas no II PND) propunham várias metas voltadas ao desenvolvimento regional mediante incentivos fiscais, o que fez com que a periferia nacional se tornasse a maior receptora de novos investimentos no período.

Para Matos (1995b) importantes mudanças na distribuição espacial da população estão em curso, sem se conhecer, no entanto, qual é o verdadeiro alcance desse fenômeno, e se as explicações existentes abrangem estes casos. É seguro dizer que as pessoas, tanto quanto as atividades, reagem aos impactos das deseconomias de aglomeração buscando localizações alternativas. Este tipo de migração pode responder claramente aos fatores de expulsão do meio urbano (notadamente aos custos de moradia e à escassez de emprego), mas pode também se associar à outro grupo de causas, não econômicas, relacionadas à melhoria da 
qualidade de vida e/ou busca de amenidades, e ao retorno às localidades de origem após a aposentadoria. É indiscutível, portanto, que boa parte da expansão da urbanização do país nas últimas décadas deriva dos efeitos multiplicadores de espraiamento da concentração urbana e industrial do Sudeste. Esse processo estimulou o adensamento da rede urbana e os vínculos de complementaridade entre as centralidades.

No contexto do debate sobre os possíveis impactos, como esclarecem Matos e Baeninger (2004), os estudos recentes sugerem:

a) transformações mais expressivas no âmbito do Estado de São Paulo, indicando um incipiente processo de desconcentração populacional; b )aumento da urbanização nas regiões e estados que se constituíram em canais da desconcentração industrial (Minas Gerais, Rio Grande do Sul, Paraná, Centro-Oeste); c) expressivos fluxos migratórios de retorno para estados tradicionalmente emissores de população; d) incremento das migrações intra-regionais; e) relativa desconcentração do sistema urbano brasileiro, com a inserção das cidades pequenas e intermediárias nas dinâmicas das aglomerações urbanas, em especial as metropolitanas (p16).

Entretanto, como defende Matos (1995), não parece plausível afirmar categoricamente sobre um amplo processo de reversão da polarização ou de desconcentração espacial. É bem provável que o país esteja passando por um ciclo de descompressão do crescimento urbano central, no qual os movimentos migratórios assumem importante papel explicativo. Nesse cenário, as regiões metropolitanas assumem um papel fundamental na compreensão desse fenômeno, tendo em conta que, como já fora mencionado, movimentos populacionais significativos têm ocorrido internamente a tais regiões ao longo das últimas décadas.

\section{3- DESMETROPOLIZAÇÃO OU PERIFERIZAÇÃO? DISCUSSÕES A PARTIR DE EVIDÊNCIAS NA REGIÃO METROPOLITANA DE BELO HORIZONTE}

Um rápido processo de crescimento urbano começou a se desenhar no Brasil a partir da década de 1940, período no qual a incipiente economia industrial deu azos à emergência de uma reorganização espacial da população no território nacional. A partir desse momento, o país presenciou um novo padrão de urbanização, essencialmente concentrador, em que a redistribuição populacional interna, em grande medida, foi direcionada aos grandes centros urbanos, notadamente os situados na região Sudeste, não obstante as tentativas governamentais de incentivar sucessivas aberturas de fronteiras agrícolas desde a década de 1930 (Martine, 1987; Patarra, 1984, Taschner e Bógus, 1986). 
Dessa forma, a expansão da rede urbana brasileira, também apoiada em uma ampliação do mercado de trabalho urbano-industrial, refletiu-se no aumento do número de cidades ${ }^{3}$, acompanhada de um esvaziamento do campo e no incremento da população urbana. As elevadas taxas de crescimento da população urbana a partir dos anos 1950, embora num ritmo menos acelerado a partir da década de 1970, encontraram esteio no declínio da população rural desde então. Merece destaque, ainda, a aceleração do grau de urbanização brasileiro, fazendo com que já em 1970 ocorresse pela primeira vez na história do país a diminuição em termos absolutos da população rural no intervalo intercensitário. A população urbana passou a representar cerca de $56 \%$ da população total, havendo, nesse contexto, uma expressiva participação da população residente na região Sudeste (com grau de urbanização de 72,7\%), fato que vem reforçar o padrão concentrador da distribuição populacional no Brasil. Nas demais regiões também passavam a predominar populações urbanas, mantendo-se tal condição nos períodos censitários subsequentes.

Nesse cenário, no qual a intensificação dos fluxos migratórios campo-cidade veio consolidar o processo de urbanização em torno das principais capitais brasileiras, as regiões urbanas passaram a se comportar como um único organismo, uma única cidade, embora subordinado a diferentes administrações municipais. Com efeito, o governo federal determinou a criação das regiões metropolitanas, de forma que a aproximação em termos políticos e administrativos entre os municípios componentes pudesse viabilizar a resolução de problemas compartilhados. Para tanto, houve um incentivo à gestão integrada através da preferência no acesso a recursos financeiros estaduais e federais àquelas cidades que participassem da elaboração e planejamento desse novo modelo de gerenciamento. Oito, dentre as nove principais RM’s do país foram criadas em 1973 (São Paulo, Belo Horizonte, Porto Alegre, Recife, Salvador, Curitiba, Belém e Fortaleza), sendo, em 1974, institucionalizada a do Rio de Janeiro.

Convém ressaltar que, ainda na década de 1960, em vários Estados o Poder Público já caminhava nessa direção, reconhecendo a questão metropolitana e colocando em prática experiências embrionárias de gestão intermunicipal, as quais contribuíram para a inclusão da questão metropolitana na Constituição Federal de 1967 e para sua manutenção na Emenda Constitucional n 1, de 1969. Assim, logo após a promulgação da Constituição de 1967 iniciaramse os estudos para a definição de critérios de delimitação e organização administrativa das regiões metropolitanas, culminando na sua institucionalização seis anos depois.

\footnotetext{
${ }^{3}$ Segundo dados dos Censos Demográficos de 1950 e 1960, ao longo dessas duas décadas houve um incremento de 877 cidades no Brasil, sendo que, destas, 33\% referem-se ao surgimento de cidades no Nordeste, $27 \%$ no Sudeste e $21 \%$ no Sul (Baeninger, 1992).
} 


\section{1- A desconcentração e os movimentos espaciais diários da população na $\mathbf{R M B H}$}

A Região Metropolitana de Belo Horizonte (RMBH), foi criada no dia 08 junho de 1973, através da Lei Complementar (federal) n 14, com a finalidade de realizar "serviços comuns de interesse metropolitano" (Mares Guia, 2001: 409). Na oportunidade, era composta por 14 municípios, a saber: Belo Horizonte, Betim, Caeté, Contagem, Ibirité, Lagoa Santa, Nova Lima, Pedro Leopoldo, Raposos, Ribeirão das Neves, Rio Acima, Sabará, Santa Luzia e Vespasiano. Em 1989, através da Constituição Estadual, foram acrescentados os municípios de Brumadinho, Esmeraldas, Igarapé e Mateus Leme. Em 1993, os municípios de Juatuba e São José da Lapa, antes integrantes de Mateus Leme e Vespasiano, respectivamente, foram também incorporados à região por meio da Lei Complementar no 26 (estadual). Em 1995, a Lei Estadual n ${ }^{\circ} 12.030$ determinou que municípios criados de emancipações de outras cidades pertencentes à RMBH, seriam nela, automaticamente incluídos. Com efeito, através da Lei Complementar (estadual) $\mathrm{n}^{\circ}$ 48, criada em novembro de 1997, foram integrados os municípios de Sarzedo e Mário Campos (que pertenciam a Ibirité até 1995), São Joaquim de Bicas (emancipado de Igarapé em 1995), Confins (que era integrante de Lagoa Santa até 1995), Florestal e Rio Manso. Em janeiro de 2000, a Lei Complementar (estadual) n ${ }^{\circ}$ 56, integrou à RMBH os municípios de Baldim, Capim Branco, Itaguara, Jaboticatubas, Matozinhos, Nova União e Taquaraçu de Minas. Por fim, em 2001, o município de Itatiaiuçu também foi integrado. Assim, a RMBH é formada atualmente por 34 municípios (abrangendo uma área de cerca de $9.179 \mathrm{~km} 2$ ) e abriga cerca de 4,8 milhões de habitantes, o que a caracteriza, em termos demográficos, enquanto a terceira maior região metropolitana do país.

A partir da década de 1970, como já demonstraram Rigotti (1994), Rigotti e Rodrigues (1994), Matos (1995a), Brito (1992), dentre outros, já era perceptível uma desaceleração no rítmo de crescimento de Belo Horizonte. A partir desse momento, os municípios da periferia da RMBH vêm apresentando incrementos populacionais bem mais significativos do que a própria Capital mineira. Como pode ser observado na Tabela $1 \mathrm{em}$ anexo, os municípios periféricos experimentaram taxas de crescimento populacional anual da ordem de 6,84\%, 5,01\% e 4,40\% entre os períodos de 1970/1980, 1980/1991 e 1991/2000, respectivamente. Nesses mesmos períodos, o município de Belo Horizonte apresentou taxas anuais de $3,73 \%, 1,15 \%$ e $1,10 \%{ }^{4}$. Esses diferenciais no ritmo de crescimento da periferia metropolitana tiveram reflexo na evolução da participação do núcleo metropolitano nos estoques totais de população na região. Desde 1970, a periferia metropolitana vem crescendo em volume e na proporção da população regional. Em 2000, 48,63\% da população da região metropolitana residia fora de Belo Horizonte (em 1970 essa proporção era de apenas 33,59\%). 
Essa queda na participação da população residente em Belo Horizonte na região metropolitana poderia suscitar pelo menos duas conclusões aparentemente antagônicas: a perda de centralidade ou a ampliação do campo de polarização do núcleo metropolitano. A primeira hipótese baseia-se em um provável deslocamento das atividades econômicas e da população do core para a periferia, diminuindo o peso econômico e demográfico da capital. Em outra perspectiva, o crescimento da periferia é visto como resultado do extravasamento do core metropolitano, o que ao contrário do que se imaginaria, representaria um crescimento da polarização e a densificação da rede urbana regional nuclear.

Ainda que pareça contraditório, uma análise acerca dos fluxos de população entre o núcleo e os municípios da periferia metropolitana parece indicar que ainda que Belo Horizonte tenha mantido sua centralidade, há um ganho de autonomia de um número razoável de municípios na região. Vários municípios antes descritos como meras "cidades dormitórios" nas décadas de 1960 e 1970, além de ampliar suas inter-relações com o core, apresentam forte desenvolvimento de determinadas funcionalidades eminentemente urbanas, o que tem permitido que uma crescente parcela da população local tenha suas atividades econômicas/profissionais desenvolvidas no próprio município de residência, o que tem diminuído a proporção e/ou o volume daqueles que fazem movimentos diários entre a periferia e núcleo metropolitano.

\footnotetext{
${ }^{4}$ Os fluxos migratórios inter e intraregional tiveram fundamental importância na queda do ímpeto de crescimento de Belo Horizonte. Desde a década 1970/1980, como apontava Rigotti (1994), as taxas líquidas de migração já eram favoráveis a periferia metropolitana, com destaque aos ganhos de população dos municípios de Ribeirão da Neves, Betim, Contagem, Ibirité, Santa Luzia e Vespasiano.
} 


\section{4-MOBILIDADE PENDULAR INTRAMETROPOLITANA E INSERÇÃO OCUPACIONAL DA POPULAÇÃO}

Uma primeira análise acerca dos movimentos diários de população na região metropolitana com destino a Belo Horizonte pode ser obtida a partir dos dados extraídos dos Censos Demográficos de 1980 e $2000^{5}$. Se compararmos esses dois momentos, nota-se um expressivo aumento do número de pessoas residentes nos municípios da periferia metropolitana que declararam trabalhar ou residir em Belo Horizonte (de 82.307 em 1980 para 266.501 em 2000), ainda que proporcionalmente as alterações tenham sido menos expressivas (de 9,19\% a 12,62\%). Como pode ser observado a partir da Figura 1, em vários municípios, notadamente aqueles mais próximos ao núcleo (a chamada periferia imediata), houve uma ampliação da participação da população residente que residia ou estudava em Belo Horizonte (mais detalhes ver Tabela 2 em anexo). Em Ribeirão das Neves e Sabará, por exemplo, essa participação em 2000 era superior a 20\% da população residente total. Também são expressivas as proporções registradas nos municípios de Santa Luzia, Igarapé e Vespasiano. Cabe destacar, ainda, o volume expressivo representado pelos movimentos procedentes de Contagem, que envolveram quase 70 mil pessoas deslocando diariamente para Belo Horizonte. Ainda em relação ao volume, o caso de Ribeirão das Neves também é exemplar. Mais de 50 mil pessoas residentes nesse município trabalham ou estudam no núcleo metropolitano.

Mesmo que boa parte do aumento no número de pessoas que declaram trabalhar ou residir em Belo Horizonte seja um resultado natural do crescimento populacional da periferia metropolitana verificada a partir da década de 1970, é notório o alto grau de polarização exercido pela capital mineira. Contudo, esses dados censitários não permitem desagregar aqueles que realizam o movimento para fins definidamente de trabalho. São incluídos nesse volume aqueles que se deslocam com finalidade exclusiva de estudo, o que envolve jovens fora da idade laboral. Uma rica fonte auxiliar de dados, que permite identificar os deslocamentos de casa para o trabalho, refere-se as Pesquisas Domiciliares de Origem e Destino (ODs), comumente realizadas a cada dez anos ${ }^{6}$. Essas pesquisas tiveram a sua primeira versão em 1972, antes mesmo da instituição formal das RMs no Brasil, sendo inicialmente desenvolvida pelo antigo PLAMBEL (Planejamento da Região Metropolitana de Belo Horizonte). A segunda pesquisa, também realizada pelo PLAMBEL, foi iniciada em 1981 e concluída em 1982.

\footnotetext{
${ }^{5}$ Essa variável foi excluída do questionário da amostra no Censo de 1991, sendo retomada no levantamento subsequente.
} 
Figura 1

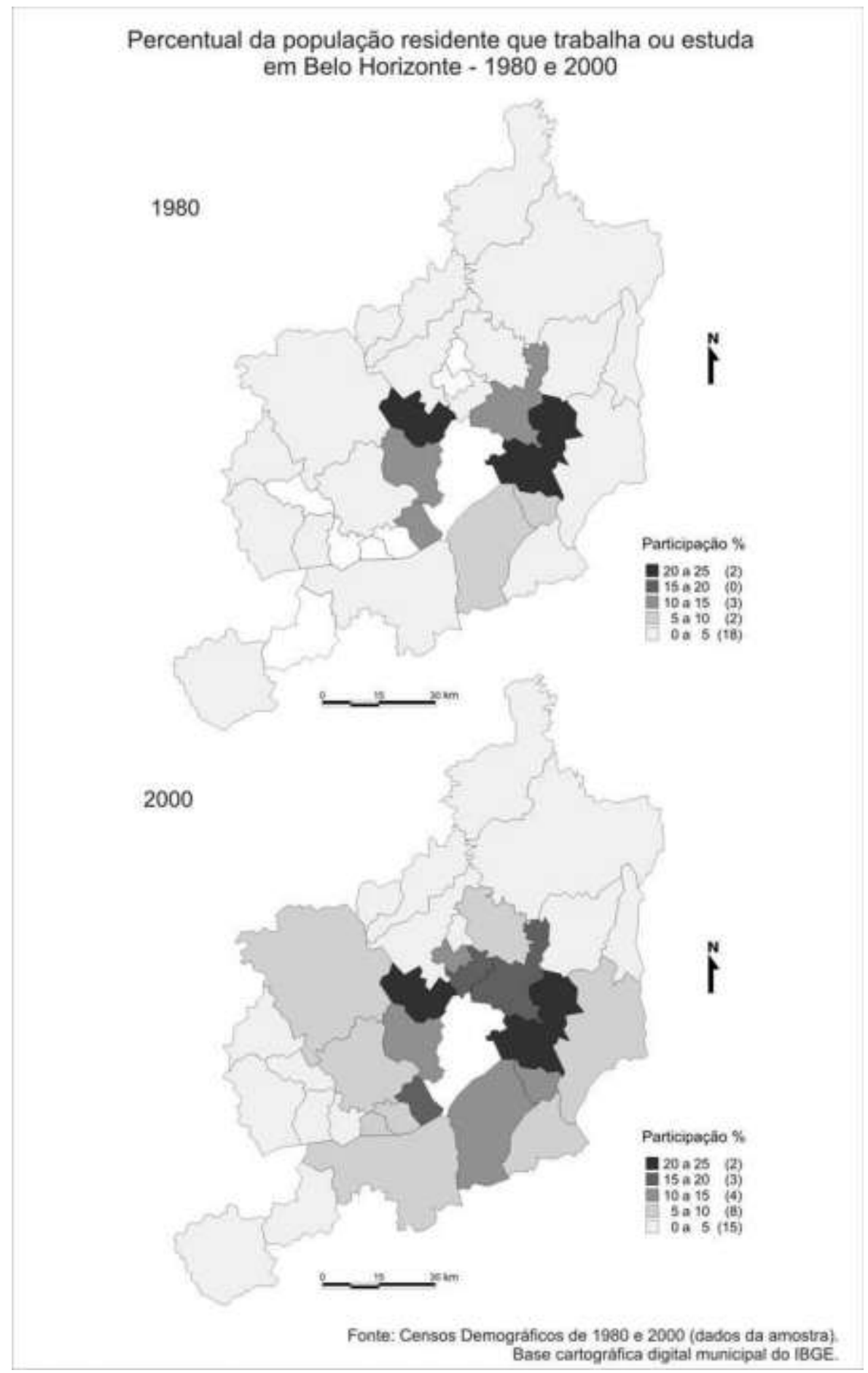

${ }^{6}$ As ODs fornecem informações diversas para cada um dos municípios em análise, como por exemplo, aspectos socioeconômicos e demográficos relativos ao indivíduo e ao domićlío de moradia, o tempo gasto entre a moradia e o local de trabalho, o modo de transporte utilizado, entre outros. 
Em 1992, a terceira versão da pesquisa foi realizada pelo NUCLETRANS (Núcleo de Transportes da Escola de Engenharia da UFMG), em convênio com a TRANSMETRO (Transportes Metropolitanos). A quarta e, até então, mais atual pesquisa OD relacionada à RMBH, foi realizada entre os anos de 2001 e 2002, sendo desenvolvida pela Fundação João Pinheiro (FJP). As bases das ODs de 1992 e 2001 permitem identificar os movimentos populacionais diários do local de residência e de trabalho da população residente nos municípios da região metropolitana. Essas informações possibilitam traçar os vetores de deslocamento intrametropolitano, bem como algumas das características ocupacionais da população protagonista desses movimentos ${ }^{7}$.

Os resultados extraídos das ODs também confirmam a intensificação dos movimentos populacionais entre os municípios da periferia e o núcleo metropolitano. Os deslocamentos diários com destino a Belo Horizonte passaram de 137.098 em 1992 para 164.388 em 2001. No entanto, se em 1992 representavam 37,55\% do total de deslocamentos residênciatrabalho no interior da região metropolitana, essa proporção foi reduzida a 22,08\% em 2001 (excluídos os movimentos dentro do próprio município de Belo Horizonte). A análise desagregada por município indica particularidades especialmente relevantes, como pode ser observado na Figura 2. No eixo norte, onde se destacam os municípios de Ribeirão das Neves, Vespasiano e Santa Luzia, foi notória a queda acentuada na proporção daqueles que se deslocavam para o trabalho em Belo Horizonte. No caso específico de Ribeirão das Neves, que envolve um volume maior de população, os percentuais caíram de 69,18\% em 1992 para 39,17\% em 2001. Há, todavia, casos em que o movimento em direção ao núcleo experimentou leve crescimento. Um importante exemplo foi Nova Lima (como também Raposos e Brumadinho), onde a proporção evoluiu de 20,49\% para 28,05\% (mais detalhes ver Tabela 3 em anexo).

\footnotetext{
${ }^{7}$ A opção dessa pesquisa foi de analisar os deslocamentos referentes ao trabalho principal, tendo em vista a possibilidade de uma mesma pessoa ter mais de uma ocupação.
} 
Figura 2

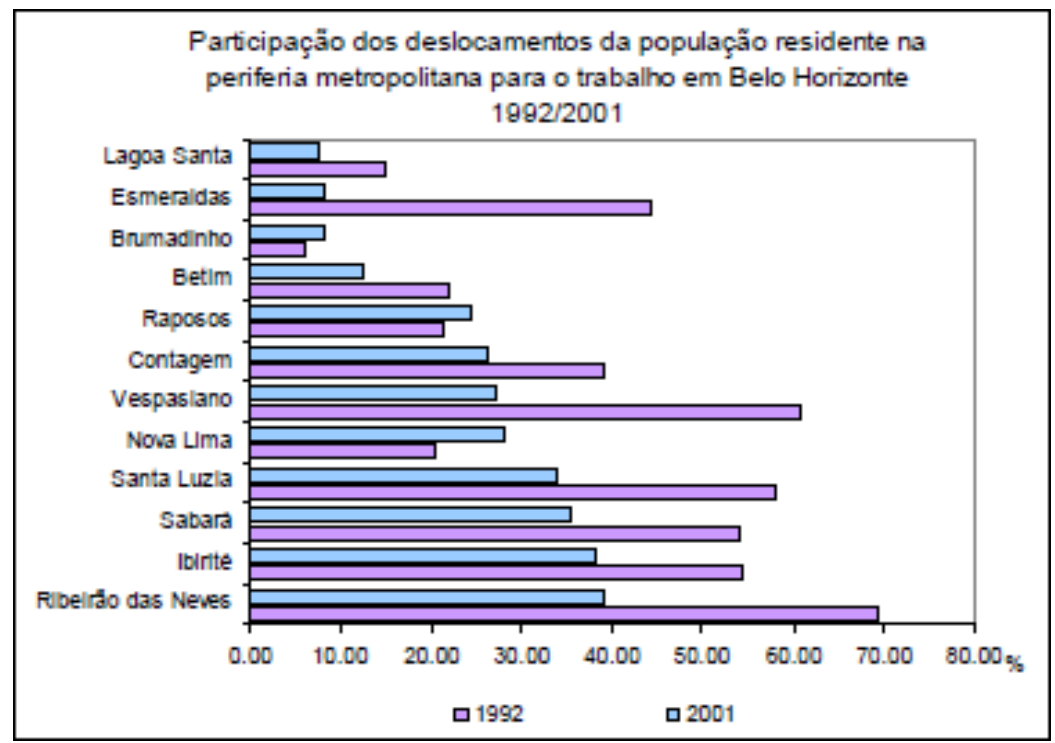

Fonte: ODs 1992 e 2000.

Nesse mesmo período, associado à diminuição relativa dos deslocamentos casa na periferia-trabalho na capital, registra-se um forte crescimento dos deslocamentos casatrabalho realizados no próprio município de residência. De 52,78\% de movimentos intramunicipais em 1992, essa proporção evoluiu para 67,77\% em 2001. Na Figura 3 observa-se que dos vinte e dois municípios com informação disponível em 1992, em sete a participação dos que trabalhavam no mesmo município de residência era inferior a 50\% (Sabará, Santa Luzia, Esmeraldas, Sarzedo, Ribeirão das Neves, Vespasiano e Ibirité). Em 2001, apenas o município de Ibirité manteve-se nessa situação, enquanto treze municípios exibiam proporções variando entre $50 \%$ e $75 \%$. Trata-se, em sua grande maioria, de municípios limítrofes com Belo Horizonte. Além de Contagem e Betim, com expressivo volume de população ocupada dentro do município, destacaram-se Ribeirão das Neves e Santa Luzia (ambos com valores superiores a 30 mil). 
Figura 3

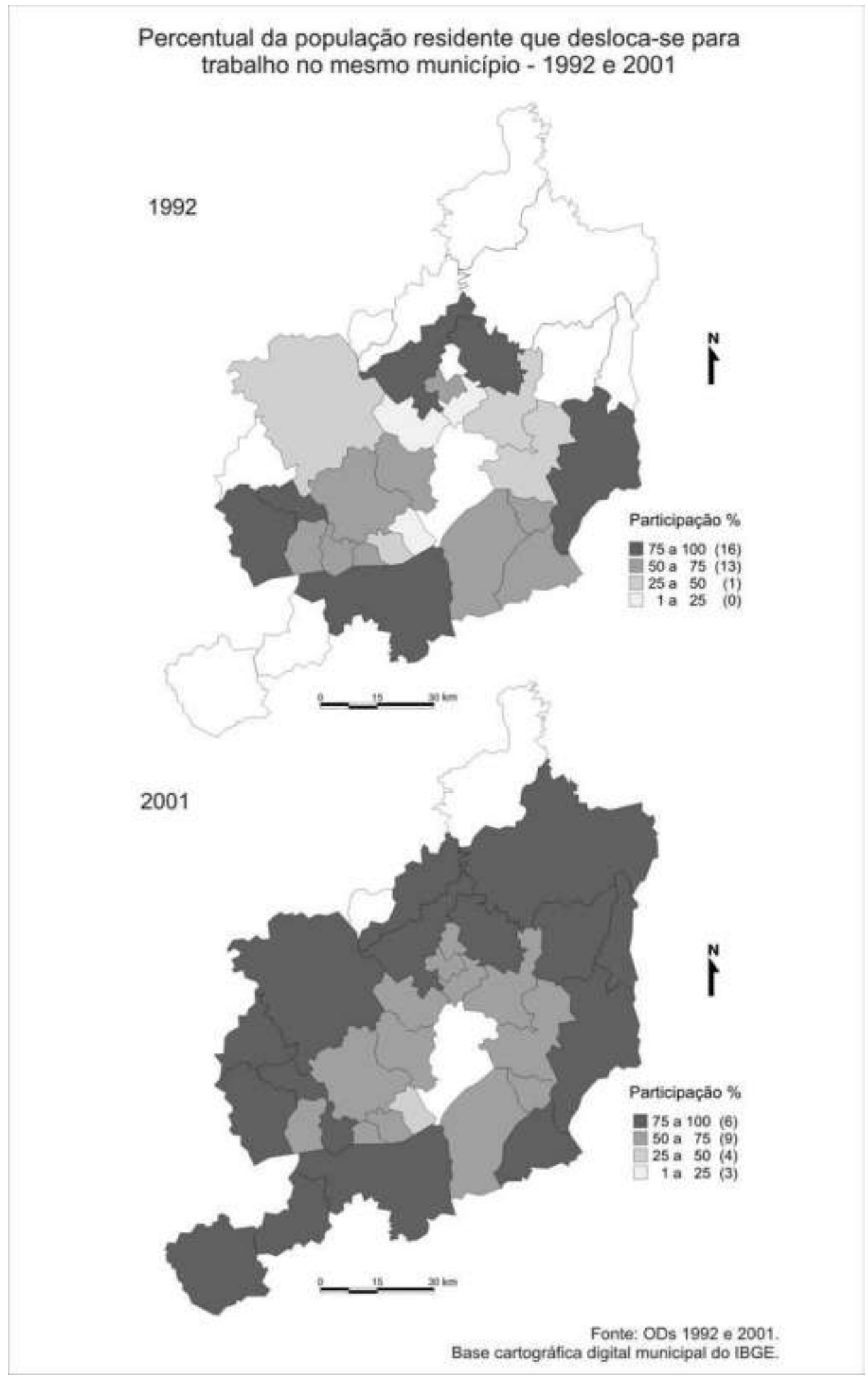

Cadernos do Leste 
Esse crescimento na absorção de mão de obra nos municípios da periferia sugere um crescimento na oferta de postos de trabalho e o fortalecimento e das economias locais na região. Mesmo que Belo Horizonte continue absorvendo boa parte da força de trabalho metropolitana, há sinais de ganho de autonomia econômica dos municípios do entorno, notadamente daqueles com maior peso demográfico, próximo a capital. Esses municípios, não obstante as especificidades, passaram a absorver uma parcela maior de trabalhadores e a oferecer postos de trabalho com maiores requisitos de qualificação e/ou especialização, sobretudo nos setores de prestação de serviços e de comércio varejista 8 .

Apesar de algumas características marcantes em termos ocupacionais, da parcela da população que declarou trabalhar no próprio município de residência, existe o predomínio das atividades dos chamados serviços diversos, uma vez que incorporam 44,03\% do total de ocupados (ver Tabela 1). Dignos de nota também são o comércio varejista, a indústria e extração mineral (nos municípios de Betim, Santa Luzia, Pedro Leopoldo e Ibirité) e os serviços públicos (com forte presença em quase todos os municípios). São, em sua maioria, atividades econômicas tipicamente urbanas, o que aponta para o fato de os municípios com maior taxa de ocupação da RMBH apresentarem incrementando ali suas atividades terciárias, várias delas de baixa qualificação, particularmente aquelas de tipo serviços pessoais, domésticos, de conservação e limpeza.

A comparação das informações contidas nas Tabelas 1 e 2, relativas às populações que fazem e não fazem deslocamentos pendulares na RMBH, mostram algumas diferenças, que permitem ratificar algumas conclusões: 1) Os serviços públicos constituem uma importante fonte de empregos a ocupar principalmente a força de trabalho local (provavelmente os de menor remuneração); 2) Setores econômicos tipicamente urbanos vão ocupar, indiscriminadamente, muita mão-de-obra em uma área metropolitana, o melhor exemplo é o do comércio varejista, com a forte presença de pendulares ocupados em lojas e estabelecimentos sediados no core metropolitano (24,47\% contra 18,46\%); 3 ) Os serviços diversos também envolvem mais mãodeobra de trabalhadores pendulares (47,99\% contra 44,03\%), mas nesse caso a pendularidade aglutina um percentual não desprezível de pessoas de maior renda que moram em condomínios fechados nos municípios contíguos a Belo Horizonte, tais como Nova Lima, Brumadinho, Esmeraldas ou Sabará (dados não mostrados).

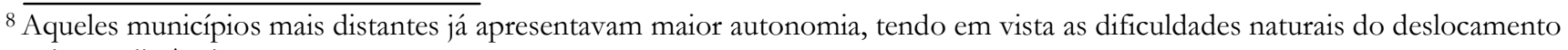
em longa distância.
} 


\section{CONSIDERAÇÕES FINAIS}

Desde a década de 1980, os possíveis efeitos do processo de desconcentração espacial e dispersão da população têm atraído atenção especial de vários pesquisadores brasileiros. Depois de décadas em que um país enfrentou uma forte concentração da população e das atividades econômicas nos principais metrópoles do Sudeste, surgiram evidências acerca da possível mudança de padrão. Mesmo que nossa realidade social e econômica seja eminentemente distinta, várias tentativas buscaram avaliar essa hipótese para o caso brasileiro. Ainda que esse debate não tenha se traduzido em consenso, algumas evidências parecem sugerir, se não uma desconcentração nos moldes clássicos, pelo menos o fortalecimento de determinadas especialidades além do core metropolitano. Não obstante a essas incertezas, também são ainda incipientes as pesquisas que enfatizam os movimentos espaciais da população nessa análise, seja pela definição clássica da migração ou mesmo pela dita mobilidade pendular.

Nesse contexto, a Região Metropolitana de Belo Horizonte compreende um espaço especialmente peculiar. Na metade do século passado a capital do estado tinha pouco mais de 350 mil habitantes. Em menos de cinqüenta anos Belo Horizonte teve um forte surto de crescimento demográfico e uma posterior arrefecimento, resultado, em boa medida, da inversão no saldo migratório intrametropolitano. A partir desse momento, vários centros urbanos se fortaleceram na periferia metropolitana, apresentando níveis de crescimento populacional significativamente superior ao núcleo e um grande fluxo de imigrantes. Se a dispersão espacial da população residente é insuficiente para caracterizar um quadro de desconcentração espacial, como proposto na economia regional, parece haver outros sinais de ganho de autonomia econômica em diversos espaços além do core. Essas evidências vão além de realidade encontrada em Contagem e Betim (vetor Oeste), importantes centros de expansão do parque industrial, mas também podem ser identificadas em municípios do eixo norte da região metropolitana, como em Ribeirão das Neves, Santa Luzia e Vespasiano, por exemplo.

Uma forma de avaliar as alterações na centralidade do espaço metropolitana é pela análise dos movimentos diários de população. Com base nas pesquisas de Origem e Destino de 1992 e 2001, foi possível identificar uma sensível queda na proporção dos fluxos diários do tipo residência/trabalho dos municípios da periferia com destino ao núcleo metropolitano. Paralelamente, e associado a essa mudança, em grande parte dos municípios da periferia houve um expressivo crescimento no volume daqueles que se deslocavam dentro do próprio município de residência. $\mathrm{Na}$ estrutura ocupacional dessas populações nota-se uma importante concentração na categoria serviços diversos, com menor participação do comércio varejista, 
indústria e serviços públicos. Quando comparada a estrutura daqueles de dirigem-se a Belo Horizonte diariamente, os resultados são bem semelhantes, destacada o maior peso dos serviços diversos e do comércio varejista.

Tabela 1

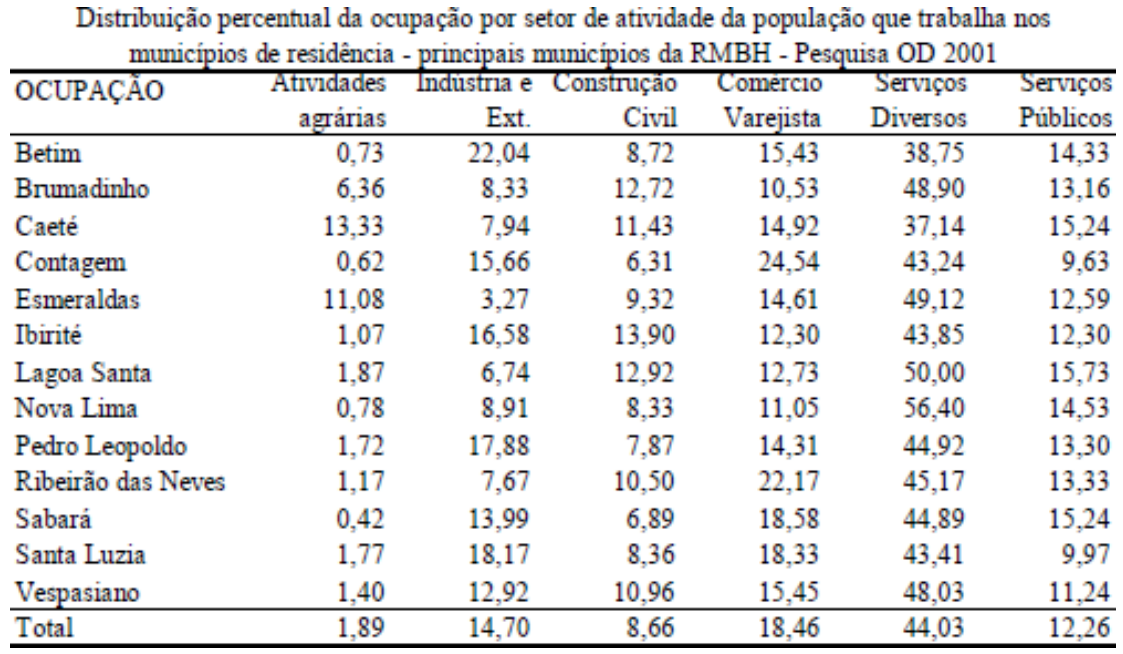

Fonte: OD’s 1992 e 2000

Tabela 2

\begin{tabular}{|c|c|c|c|c|c|c|}
\hline$\overline{\text { OCUPAÇÁO }}$ & $\begin{array}{r}\text { AtIvidades } \\
\text { agrárias }\end{array}$ & $\begin{array}{r}\text { Industraa e } \\
\text { Ext. }\end{array}$ & $\begin{array}{r}\text { Construçáa } \\
\text { Civil } \\
\end{array}$ & $\begin{array}{r}\text { Comercio } \\
\text { Varejista }\end{array}$ & $\begin{array}{l}\text { Serviços } \\
\text { Diversos }\end{array}$ & $\begin{array}{l}\text { Serviços } \\
\text { Públicos }\end{array}$ \\
\hline$\overline{\text { Betim }}$ & 0,00 & 8,33 & 11,46 & 22,92 & 49,48 & 7,81 \\
\hline Brumadinho & 0,00 & 6,52 & 6,52 & 10,87 & 63,04 & 13,04 \\
\hline Caeté & 0,00 & 12,00 & 12,00 & 12,00 & 48,00 & 16,00 \\
\hline Contagem & 0,24 & 10,34 & 4,64 & 24,02 & 46,14 & 14,63 \\
\hline Esmeraldas & 0,00 & 11,63 & 11,63 & 18,60 & 48,84 & 9,30 \\
\hline Ibirité & 0,00 & 16,76 & 10,40 & 27,17 & 41,04 & 4,62 \\
\hline Lagoa Santa & 0,00 & 24,49 & 6,12 & 10,20 & 46,94 & 12,24 \\
\hline Nova Lima & 0,00 & 6,85 & 5,48 & 17,81 & 58,45 & 11,42 \\
\hline Pedro Leopoldo & 0,00 & 22,73 & 4,55 & 18,18 & 36,36 & 18,18 \\
\hline Ribeirão das Neves & 0,21 & 8,09 & 9,57 & 28,51 & 45,96 & 7,66 \\
\hline Sabará & 0,00 & 10,51 & 7,46 & 21,36 & 52,20 & 8,47 \\
\hline Santa Luzia & 0,00 & 8,55 & 5,13 & 24,79 & 54,70 & 6,84 \\
\hline Vespasiano & 0,00 & 5,10 & 14,01 & 28,66 & 45,86 & 6,37 \\
\hline Total & 0,11 & 10,01 & 7,56 & 24,47 & 47,99 & 9,86 \\
\hline
\end{tabular}

Fonte: OD’s 1992 e 2000.

Cadernos do Leste 


\section{REFERÊNCIAS BIBLIOGRÁFICAS}

AZZONI, C. Indústria e Reversão da Polarização no Brasil. Ensaios Econômicos -IPE/USP, São Paulo, n.58, 1986.

BAENINGER, R. O processo de urbanização no Brasil: características e tendências. In: BÓGUS, L.M.M.; WANDERLEY, L.E.W.(orgs.). A luta pela cidade em São Paulo. Cortez Editora. São Paulo, 1992, p. 11-28.

BRITO, F. Mobilidade espacial e expansão urbana: o caso da Região Metropolitana de Belo

Horizonte. Anais do X Encontro de Estudos Populacionais. Brasília, 1992, v.2, p.771-788.

CANO, W. Raízes da Concentração Industrial em São Paulo, 2 ed. São Paulo: TA Queiroz, 1977.

CARVALHO, J. A. M. A dinâmica demográfica no Brasil: tendências recentes e perspectivas. Revista Brasileira de Estudos Populacionais, São Paulo, v. 1, p. 05-23, 1997.

CARVAlHO, J. A. M., RIGOTTT, J. I. Análise das metodologias de mensuração das migrações. In: ENCONTRO NACIONAL SOBRE MIGRAÇÃO, 1998, Curitiba. Anais ... Curitiba: IPARDES/ABEP, 1998.

DINIZ, C.C. "Desenvolvimento poligonal no Brasil; nem desconcentração, nem contínua polarização". Nova Economia - Revista de Ciências Econômicas da UFMG, Belo Horizonte, vol. 31, n. 11, 1993, pp. 35-64.

GREENWOOD, M. Migrações internas nos Estados Unidos; uma revisão da literatura. In: MOURA, A. M. (Coord). Migração interna; textos selecionados. Fortaleza: Banco do Nordeste do Brasil, 1980, p. 733-77. 1980.

HADDAD, P. Economia Regional; teorias e métodos de análise, Recife, Banco do Nordeste do lBrasil, 1980.

MARES GUIA, V. R. A gestão na Região Metropolitana de Belo Horizonte: avanços e limites. In: FERNANDES, E. (org.). Direito urbanístico e política urbana no Brasil. Belo Horizonte: Del Rey, 2001.

MARTINE, G.. A redistribuição espacial da população brasileira durante a década de 80 . Textos para Discussão 329, Brasília, IPEA, 1994. 43p.

MARTINE, G. Migração e metropolização. In: São Paulo em Perspectiva. São Paulo, Fundação SEADE 1(2)7, 1987.

MATOS, R. Dinâmica migratória e desconcentração da população na macrorregião de Belo Horizonte. Belo Horizonte. CEDEPLAR (tese de doutorado), 1995 a. 
, "Questões teóricas acerca dos processos de concentração e desconcentração da população no espaço". In: Revista Brasileira de Estudos Populacionais. São Paulo, 1995, p. 3558.

MATOS, R. e BENINGER, R. Migração e urbanização no Brasil: processos de concentração e desconcentração espacial e o debate recente. Cadernos do Leste. IGC/UFGM, v.1, n.1, Belo Horizonte, 2004, p.7-44.

NEGRI, B. Concentração e desconcentração industrial em São Paulo (1880-1990). Campinas:

Ed. UNICAMP, 1996.

PATARRA, N. Dinâmica populacional e urbanização no Brasil: período pós-30. In: FAUSTO, Boris, História geral da civilização brasileira: O Brasil republicano, São Paulo, Difel, t.3, v.4, 1984, p. 247-268.

REDWOOD III, J. Reversion de polarizacion, ciudades secundarias y eficiencia en el desarrollo nacional: una vison teorica aplicada al Brsil contemoraneo. Revista Latinoamericana de Estudios Urbanos Regionales, Santiago, vol 11, n.32, dez. 1984

RICHARDSON, H. "Polarization reversal in developing countries". The Regional Science Association Papers, Los Angeles, vol. 45, nov. 1980.

RIGOTTI, J. I. R. Técnicas de mensuração das migrações a partir de dados censitários: aplicação aos casos de Minas Gerais e São Paulo. Belo Horizonte: UFMG/CEDEPLAR, 1999. (tese de doutorado em demografia)

RIGOTTI, J. I. R. e RODRIGUES, J. N. Distribuição espacial da população na região Metropolitana de Belo Horizonte. Anais do IX Encontro de Estudos Populacionais. Caxambú,1994, v.1, p.435-456

TASCHNER, S. P. e BÓGUS, L.M.M. Mobilidade Espacial da População Brasileira: Aspectos e Tendências. In: Revista Brasileira de Estudos de População, jul-dez, 1986.

TOWNROE, P. e KEEN, D. M. "Polarization reversal in the state of São Paulo, Brazil”. Journal of the Regional Studies Association, Cambridge, vol. 18, n. 1, fev. 1984. 


\section{ANEXOS}

Tabela 1

População residente e taxa de crescimento populacional anual - 1970 a 2000

\begin{tabular}{|c|c|c|c|c|c|c|c|}
\hline \multirow{2}{*}{ Município } & \multicolumn{4}{|c|}{ População Total } & \multicolumn{3}{|c|}{ Crescimento populacional anual } \\
\hline & 1970 & 1980 & 1991 & 2000 & $1970 / 1980$ & $1980 / 1991$ & $1991 / 2000$ \\
\hline Belo Horizonte & \multicolumn{2}{|c|}{1.235 .10380 .855} & 2.020 .161 & 2.229 .697 & 3,73 & 1,15 & 1,1 \\
\hline Betim & \multicolumn{2}{|c|}{37.81517 .8784 .183} & 170.934 & 303.588 & 8,33 & 6,65 & 6,59 \\
\hline Brumadinho $(*)$ & \multicolumn{2}{|c|}{$25.166111 .23 \$ 7.964$} & 19.308 & 26.607 & 0,05 & 0,66 & 3,63 \\
\hline Caeté & \multicolumn{2}{|c|}{$15.698 \times x 80.634$} & 33.251 & 36.278 & 1,99 & 0,75 & 0,97 \\
\hline Contagem & \multicolumn{2}{|c|}{$13.946 \times 880.477$} & 449.588 & 536.408 & 9,69 & 4,38 & 1,98 \\
\hline Esmeraldas $(*)$ & $\mathrm{xxx}$ & 16.206 & 24.298 & 45.784 & 0,32 & 3,75 & 7,29 \\
\hline Florestal & 4.330 & $\mathrm{xxx}$ & $\mathrm{xxx}$ & 5.636 & $\mathrm{xxx}$ & $\mathrm{xxx}$ & $\mathrm{xxx}$ \\
\hline Ibirité & $\mathrm{XXX}$ & 31.939 & 78.090 & 132.843 & 8,64 & 8,47 & 6,08 \\
\hline Sarzedo $(* *)$ & 5.330 & $\mathrm{xxx}$ & $\mathrm{xxx}$ & 17.240 & $\mathrm{xxx}$ & $\mathrm{xxx}$ & $\mathrm{xxx}$ \\
\hline Mário Campos (**) & 12.060 & $\mathrm{xxx}$ & $\mathrm{xxx}$ & 10.525 & $\mathrm{xxx}$ & $\mathrm{xxx}$ & $\mathrm{xxx}$ \\
\hline Igarapé $(*)$ & $\mathrm{XXX}$ & 10.253 & 15.957 & 24.269 & 9 & 4,1 & 4,77 \\
\hline São Joaquim de Bicas $(*)(* *)$ & 9.169 & $\mathrm{xxx}$ & $\mathrm{xxx}$ & 18.156 & $\mathrm{xxx}$ & $\mathrm{xxx}$ & $\mathrm{xxx}$ \\
\hline Itatiaiuçu $(* * *)$ & $\mathrm{xxx}$ & 5.246 & 7.366 & 8.517 & $-0,16$ & 3,13 & 1,63 \\
\hline Lagoa Santa & 33.992 & 17.163 & 26.641 & 37.756 & 3,59 & 4,08 & 3,95 \\
\hline Confins $(* *)$ & 20.670 & $\mathrm{XxX}$ & $\mathrm{xxx}$ & 4.797 & $\mathrm{xxx}$ & $\mathrm{xxx}$ & $\mathrm{xxx}$ \\
\hline Mateus Leme (*) & 10.133 & 13.334 & 17.597 & 24.124 & 3,82 & 2,55 & 3,57 \\
\hline Juatuba $(*)(* *)$ & 9.707 & $\mathrm{xxx}$ & $\mathrm{Xxx}$ & 15.755 & $\mathrm{xxx}$ & $\mathrm{xxx}$ & $\mathrm{xxx}$ \\
\hline Nova Lima & 5.118 & 41.223 & 52.400 & 64.295 & 1,95 & 2,2 & 2,3 \\
\hline Pedro Leopoldo & $\mathrm{xxx}$ & 29.999 & 41.594 & 53.825 & 3,8 & 3,02 & 2,91 \\
\hline Raposos & 45.149 & 11.810 & 14.242 & 14.268 & 1,54 & 1,72 & 0,02 \\
\hline Ribeirão das Neves & 25.301 & 67.257 & 143.853 & 246.589 & 21,36 & 7,16 & 6,17 \\
\hline Rio Acima & 12.429 & 5.069 & 7.066 & 7.651 & $-0,1$ & 3,07 & 0,89 \\
\hline Rio Manso & $\mathrm{Xxx}$ & $\mathrm{xxx}$ & $\mathrm{xxx}$ & 4.644 & $\mathrm{xxx}$ & $\mathrm{xxx}$ & $\mathrm{xxx}$ \\
\hline Sabará & 1.650 .152 & 64.204 & 89.740 & 114.557 & 3,58 & 3,09 & 2,75 \\
\hline Santa Luzia & 415.122 & 59.892 & 137.825 & 184.721 & 9 & 7,87 & 3,31 \\
\hline Vespasiano & & 17.924 & 48.012 & 76.328 & 3,73 & 9,37 & 5,29 \\
\hline São José da Lapa (**) & & $\mathrm{Xxx}$ & $\mathrm{xxx}$ & 15.009 & $\mathrm{xxx}$ & $\mathrm{xxx}$ & $\mathrm{xxx}$ \\
\hline Total RMBH & & 2.585 .632 & 3.397 .923 & 4.259 .867 & 4,59 & 2,51 & 2,54 \\
\hline Total RRM & & 804.777 & 1.377 .762 & 2.030 .170 & 6,84 & 5,01 & 4,4 \\
\hline
\end{tabular}

Fonte: IBGE, Censos Demográficos de 1970, 1980,1991 e 2000.

Notas:(*) Municípios que não compunham a RMBH em 1980. (**) Municípios

emancipados na década de 1990.(***)

Município incorporado à RMBH em 2001. 
Tabela 2

População residente, número e percentual de população que trabalha ou estuda em Belo Horizonte 1980 e 2000

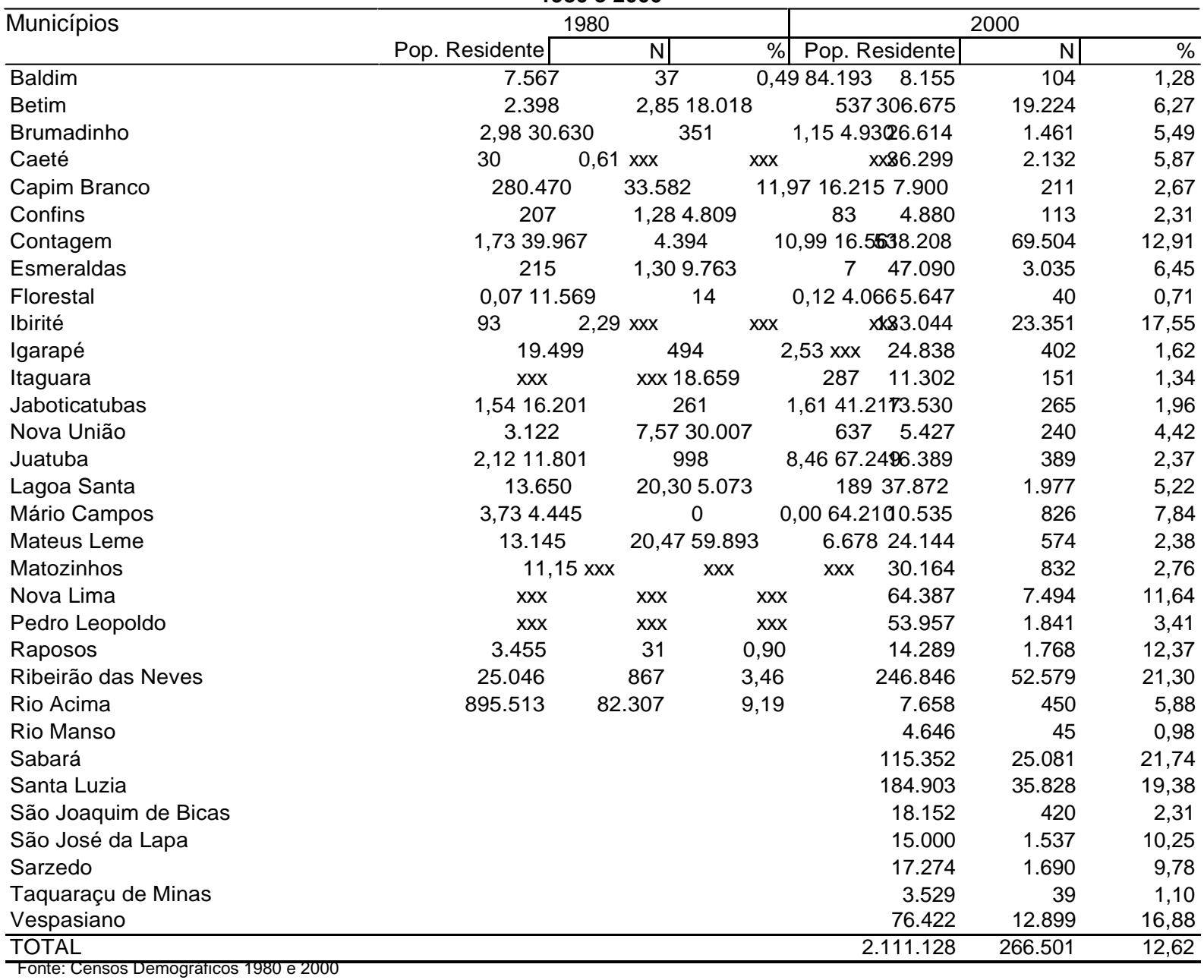
(dados da amostra) 
Tabela 3

Movimentos diários do local de residência ao trabalho, com destino a Belo Horizonte e ao próprio município de residência origem residência e destino trabalho principal - 1992 e 2001

\begin{tabular}{|c|c|c|c|c|c|c|c|c|c|c|}
\hline \multirow{3}{*}{ Município } & \multicolumn{5}{|c|}{1992} & \multicolumn{5}{|c|}{2001} \\
\hline & \multirow{2}{*}{ Total } & \multicolumn{2}{|c|}{ Belo Horizonte } & \multicolumn{2}{|c|}{ Proprio Município } & \multirow{2}{*}{ Total } & \multicolumn{2}{|c|}{ Belo Horizonte } & \multicolumn{2}{|c|}{ Proprio Município } \\
\hline & & $\mathrm{N}$ & $\%$ & $\mathrm{~N}$ & $\%$ & & $\mathrm{~N}$ & $\%$ & $\mathrm{~N}$ & $\%$ \\
\hline Pedro Leopoldo & 11.037 & 496 & 4,50 & 9.982 & 90,44 & 23.897 & 578 & 2,42 & 21.848 & 91,43 \\
\hline Caeté & 7.311 & 183 & 2,50 & 6.582 & 90,03 & 12.844 & 805 & 6,27 & 10.977 & 85,46 \\
\hline Brumadinho & 3.328 & 210 & 6,31 & 2.897 & 87,04 & 14.845 & 1.244 & 8,38 & 12.492 & 84,15 \\
\hline Juatuba & 1.509 & 66 & 4,34 & 1.257 & 83,32 & 7.401 & 307 & 4,15 & 5.609 & 75,78 \\
\hline Lagoa Santa & 14.219 & 2.140 & 15,05 & 10.924 & 76,83 & 19.152 & 1.469 & 7,67 & 15.898 & 83,01 \\
\hline Mateus Leme & 3.621 & 245 & 6,76 & 2.776 & 76,66 & 9.656 & 82 & 0,85 & 8.692 & 90,02 \\
\hline Nova Lima & 13.712 & 2.809 & 20,49 & 9.874 & 72,01 & 26.370 & 7.398 & 28,05 & 17.821 & 67,58 \\
\hline lgarapé & 3.017 & 126 & 4,16 & 2.076 & 68,82 & 10.618 & 470 & 4,43 & 7.661 & 72,15 \\
\hline Rio Acima & 1.579 & 319 & 20,19 & 1.051 & 66,56 & 3.114 & 481 & 15,45 & 2.548 & 81,82 \\
\hline São José da Lapa & 2.162 & 302 & 13,98 & 1.341 & 62,01 & 6.613 & 468 & 7,08 & 4.682 & 70,80 \\
\hline São Joaquim de Bicas & 2.362 & 219 & 9,27 & 1.455 & 61,59 & 9.068 & 394 & 4,35 & 6.801 & 75,00 \\
\hline Betim & 50.319 & 11.070 & 22,00 & 30.762 & 61,13 & 108.755 & 13.586 & 12,49 & 79.911 & 73,48 \\
\hline Raposos & 3.495 & 745 & 21,33 & 2.080 & 59,52 & 4.446 & 1.080 & 24,30 & 2.285 & 51,40 \\
\hline Contagem & 137.369 & 53.845 & 39,20 & 75.200 & 54,74 & 194.612 & 50.746 & 26,08 & 129.937 & 66,77 \\
\hline Mário Campos & 1.022 & 155 & 15,16 & 544 & 53,17 & 4.105 & 931 & 22,68 & 2.624 & 63,92 \\
\hline Sabará & 17.719 & 9.587 & 54,10 & 7.206 & 40,67 & 32.343 & 11.480 & 35,50 & 19.184 & 59,32 \\
\hline Santa Luzia & 30.862 & 17.949 & 58,16 & 11.781 & 38,17 & 52.650 & 17.782 & 33,77 & 32.633 & 61,98 \\
\hline Esmeraldas & 7.605 & 3.371 & 44,32 & 2.669 & 35,09 & 25.759 & 2.103 & 8,16 & 20.215 & 78,48 \\
\hline Sarzedo & 2.118 & 467 & 22,04 & 551 & 26,00 & 5.999 & 884 & 14,74 & 3.158 & 52,63 \\
\hline Ribeirão das Neves & 33.462 & 23.150 & 69,18 & 8.294 & 24,79 & 72.415 & 28.365 & 39,17 & 37.033 & 51,14 \\
\hline Vespasiano & 3.481 & 2.115 & 60,76 & 792 & 22,74 & 24.910 & 6.762 & 27,15 & 15.922 & 63,92 \\
\hline Ibirité & 13.821 & 7.530 & 54,48 & 2.606 & 18,85 & 41.914 & 16.002 & 38,18 & 17.820 & 42,52 \\
\hline Confins & 0 & 0 & 0 & 0 & 0 & 2.069 & 96 & 4,63 & 1.188 & 57,41 \\
\hline Florestal & 0 & 0 & 0 & 0 & 0 & 2.743 & 26 & 0,93 & 2.564 & 93,46 \\
\hline Itatiaiuçu & 0 & 0 & 0 & 0 & 0 & 3.453 & 88 & 2,54 & 3.043 & 88,14 \\
\hline Jabuticatubas & 0 & 0 & 0 & 0 & 0 & 8.503 & 167 & 1,96 & 8.169 & 96,08 \\
\hline Matozinhos & 0 & 0 & 0 & 0 & 0 & 8.843 & 212 & 2,39 & 7.150 & 80,86 \\
\hline Nova União & 0 & 0 & 0 & 0 & 0 & 1.902 & 92 & 4,82 & 1.718 & 90,36 \\
\hline Rio Manso & 0 & 0 & 0 & 0 & 0 & 2.973 & 62 & 2,07 & 2.768 & 93,10 \\
\hline Taquaraçu de Minas & 0 & 0 & 0 & 0 & 0 & 2.677 & 230 & 8,60 & 2.303 & 86,02 \\
\hline Total & 365.132 & 137.098 & 37,55 & 192.701 & 52,78 & 744.646 & 164.388 & 22,08 & 504.654 & 67,77 \\
\hline
\end{tabular}

Fonte: Dados ODs 1992 e 2001 